To cite this Article: Santonen, Teemu \& Ritala, Paavo (2014). Social Network Analysis of the ISPIM Innovation Management Community in 2009 - 2011. International Journal of Innovation Management. 18:1, 33.

DOI: $10.1142 / S 1363919614500108$

URL: http://bib.fi/11hAjO/global 


\title{
Social Network Analysis of the ISPIM Innovation Management Community in 2009 - 2011
}

\begin{abstract}
Scientific communities are bound together by common purpose and interests, and tangible evidence of the structure of such communities may be found by investigating co-authorship networks. We utilise social network analysis to examine the network structure of ISPIM (International Society for Professional Innovation Management), using co-authorship data from six ISPIM events during the years 2009-2011. We find interesting evidence of the network structure, illustrating vividly the central authors and sub-components of the network. Related to this, results reveal surprisingly tight clustering based on geographical and institutional boundaries. We also find evidence of high performing authors which span these boundaries via significantly different strategies. Overall, the results help to uncover the underlying structure of the scholarly network behind ISPIM, which helps to better understand the key contributors and their networks, and also the development points and promising research collaboration opportunities.
\end{abstract}

Keywords: Innovation Management, ISPIM, Co-authorship, Social network analysis, Community

\section{Introduction}

"ISPIM is a family". You might have heard this saying if you have participated in a conference or a symposium organised by the International Society for Professional Innovation Management (later ISPIM). When the authors of this study heard this, it made us think about what kind of family ISPIM really is. Traditionally speaking, family members have tight relationships and they collaborate with each other all the time in order to do something together and keep up their relationships. Indeed scientific communities such as ISPIM are kinds of families where you can identify fathers and mothers - key persons who keep the family running - and second cousins who you rarely meet and barely know. As in the case of a family relationship, your "second cousin" might be someone else's mother or father or vice-versa. It all depends on the viewpoint and your position in the network of relatives. Also in the case of scientific communities, social relationship and social networks are relevant, since they formulate the logic of doing and publishing research within a certain field such as innovation management.

As opposed to families, which are bonded by blood ties, scientific collaboration networks are hard to understand unless we measure and illustrate these collaboration relationships explicitly. Therefore in this study we examine the ISPIM network relationships with social network analysis method by analysing co-authorship patterns. Co-authorship analysis is an approach increasingly used to study various types of scientific communities, since it provides an unambiguous way of examining scientific collaboration and social/professional linkages (see e.g. Newman 2001, 2004; Morlacchi et. al. 2005 and Vidgen et. al. 2007). In particular, the benefit of investigating coauthorships (instead of co-citation analyses, for instance) is that it gives the possibility to investigate intentional relationships between the two or more authors (Vidgen et al., 
2007). Co-authorship, per definition, requires some level of collaboration (Newman, 2004) and can be thus considered as a sufficiently reliable indicator of actual knowledge sharing and creation between the given group of co-authors. It enables us to examine the social structures of scientific communities, revealing where the information flows, also potentially across formal boundaries within and beyond institutions, which is one major advantage of social network analysis in general (see e.g. Allen et al., 2007; Cross et al., 2002; Yan and Assimakopoulos, 2009).

The data is gathered from the published authors in ISPIM conferences and symposiums between 2009 and 2011. The goal of this study is to model and describe the structure of the ISPIM innovation management research community from the social network analysis (later SNA) point of view (for discussion on SNA, see e.g. Wasserman and Faust, 1994). By applying bibliographic analysis we identify who are the key authors, organizations and countries based on co-authorship relations and what kind of ties have been constructed among these participants. While our results provide evidence on the network structure of ISPIM community in particular, we will also discuss more generic implications of how scientific communities are formed, and what issues and development points could be considered in structuring and facilitating the formation of such communities.

This paper is organised as follows. Firstly, we introduce theoretical foundations of social networks, scientific communities, and related co-authorship analysis. Secondly, we present our research design including research objectives, data collection and key variables. Thirdly, we present our results based on network analysis. Finally, we conclude with our findings and discussion on theoretical and practical implications.

\section{Scientific communities as social networks}

Scientific communities are by nature networks between individual researchers, unified by a common agenda over topics, fields, or institutional settings (see e.g. Bourdieu, 2004). Therefore, in order to understand how individual academics and broader communities are formed and how they operate, it is important to examine the network of social relationships in which they are embedded. For this reason, we approach scientific communities in this paper through the lenses of social network analysis. Our approach is elaborated in the following sections.

\subsection{Collaboration in scientific communities}

In general, there is a growing trend of international collaboration and multi-authored papers in science (e.g. Cronin et al., 2003; Persson et al., 2004; Moody, 2004; Wagner and Leydesdorff, 2005a; Schmoch and Schubert, 2008). Moreover, it has been argued that solving complex problems requires trans-disciplinarity (Stokols 2006; Pohl and Hirsch Hadorn 2007) and cross-functional collaboration (Ruekert and Walker, 1987; Song and Montoya-Weiss, 2001), which brings people with different, yet complementary skills together to solve the identified problems. Interestingly by evaluating the level of co-authorship within a certain research domain, one can identify when a discipline or community is moving from "little science" to "big science" (Price, 1963) or becoming more professional (Beaver and Rosen, 1978). Thus, the suggested co-authorship analysis within ISPIM community would partially help to determine the maturity of this particular 
community, which formally was established in 1983 and have roots all the way back in 1973 (Holt, 2006).

It is also suggested that collaboration patterns are differing among disciplines (Egghe, 1999; Melin, 2000; Glänzel and De Lange, 2002; Abt, 2007) and countries (Wagner and Leydesdorff, 2005b). Interestingly, previous studies have shown that geographical proximity plays a key role and makes authors with closer distance more likely to collaborate with each other (Larivière et al., 2006), maybe partially because the majority of the scientific collaborations begins from a face-to-face interaction (Laudel, 2001). Moreover, so called western core countries such USA and some European countries appears to collaborate with each other more (Leydesdorff and Wagner, 2008; Schubert and Sooyramoorthy, 2010; Gazni et. al. 2012). However, also authors from developing and underdeveloped countries can benefit greatly if collaborating with authors from these core countries (Rousseau, 2000, Goldfinch, Dale, DeRouen, 2003; Onyancha and Maluleka, 2011). Finally, institutions and organizations as determinants of scientific collaboration have also gain interest among scholars (e.g Qin, 1994; Gazni et. al. 2012). Thus, besides pure co-authorship analysis, these insights call for also a country and institution-level collaboration analyses within ISPIM community.

\subsection{Motivations to collaborate}

Researchers' motivation and benefits to collaborate with each other has been quite widely studied (e.g. Kuhn 1962; Beaver and Rosen 1978, 1979a, 1979b; Barnett et. al. 1988; Melin, 2000; Autry and Griffis 2005). Several typologies have been suggested to classify the considerable number of the identified reasons (e.g. Beaver, 2000; Wagner et. al., 2005). While the main reason for research collaboration is suggested to be increased quality and quantity in terms of scientific output (Barnett et al., 1988), multiple other reasons have been identified including generic reason affecting all research domains and specific reason affecting only certain domains (Acedo et al., 2005). Among these reasons are the better likelihood to find a suitable partner due increased number of researchers, technical and interdisciplinary nature of disciplines (Hudson, 1996), valuation (Holder et. al., 2000), higher citation (Persson et. al. 2004), improved communication methods, specialization within disciplines, improved quality and greater likelihood for acceptance for publication (Laband and Tollison, 2000). Furthermore, according to Price and Gursey (1976) the maturity of author's career also has an effect on the collaboration patterns, which makes author's profile information also interesting research perspective and possible explanatory factor for network analysis' results. As classified by Acedo et al. (2006), co-authorship studies follow two main approaches: first, the reasons for collaboration and second, the social network aspect of collaboration. We focus on the latter one more explicitly though structural analysis, and based on this, also qualitatively examine the potential motivations and outcomes related to this issue.

\subsection{Social network analysis on scientific communities}

Empirical and theoretical applications of social network studies have cumulated in social sciences for over half a century already (e.g. Wasserman and Faust 1994; Watts 1999; Scott 2000). As scientific communities are social networks by their very nature, we see major value in utilizing social network analysis in this context. In fact, recently, detailed analyses have been conducted over the network structure of multiple scientific 
communities such as information systems/ECIS conference (Vidgen et al., 2007), industrial marketing/IMP conferences (Morlacchi et al., 2005), electronic markets (Fischbach et. al., 2011), open innovation (Su and Lee, 2012), crowdsourcing (Santonen et. al. 2012), logistics (Carter et al., 2010), natural sciences (Newman, 2001), neuroscience (Barabási, et al., 2002), library science (Liu et. al., 2005), management science (Acedo et al., 2006), hospitality management (Hu and Racherla, 2008, Racherla and $\mathrm{Hu}, 2010$ ), and finance (Fatt et. al. 2010). Overall, these recent studies have shown that in-depth analysis of a chosen scientific community is useful and revealing, and that social network analysis is a prominent tool in visualizing and understanding how the scientific communities are structured. In this context, we view co-authorship ties as a particularly valuable approach in examining the social structures and activity in a given scientific community since it reflects actualized collaboration (Newman, 2004).

The cumulating evidence of social network analyses conducted on scientific communities has suggested several key findings. First, a common finding is that the communities are often formed around several key scholars that are well connected to other central scholars (e.g. Acedo et al., 2006; Morlacchi et al., 2005; Vidgen et al., 2007; Fatt et. al. 2010; Fischbach et. al., 2011). These groups of key authors typically form the core group of researchers within a certain community. However, also opposite findings have been found, showing quite scattered structures, especially in new fields of inquiry (Santonen et al., 2012). Second, a lot of evidence is found on geographical or institutional clustering (Morlacchi et al., 2005; Su and Lee, 2011). In this case, there are substructures (i.e components, cliques, groups, or clusters) within the network that are connected to certain nationality of scholars or a certain discipline or institution. Third, there is increasing evidence that well-connected actors in all levels of analysis (individual researchers, institutions and countries) are performing better than less-connected ones (Acedo et al., 2006; Fischbach et. al., 2011; Ganzi et al., 2012).

\subsection{Network position and network structure in scientific communities}

Embeddedness of actors within their network of social relations is the key idea of network research, suggesting that actor's activities, resources and outcomes are strongly determined by the network they are embedded in (Borgatti et al., 2009; Kilduff and Brass, 2010). Furthermore, embeddedness suggests that there is an inertial tendency in repeating transactions over time with certain network members (Uzzi, 1996). Therefore, in academic communities it could be expected that individual scholars are most likely to collaborate in co-authoring with their existing, rather than new networks (as also shown in extant research on scientific communities).

In scientific communities, this phenomenon can be further explained with so called "homophily" argument (Vidgen et al., 2007), which relates to the tendency of the network in involving and recruiting members sharing mostly similar perspectives to the existing ones (for extensive discussion, see McPherson et al., 2001). The benefits of this tendency involve e.g. facilitation of transfer of tacit knowledge, simplified coordination, and conflict avoidance (Borgatti and Foster, 2003). From this perspective, the collaboration in co-authoring starts naturally with similar alters representing similar disciplines and backgrounds.

While co-authoring between similar alters helps to facilitate collaboration in many ways, there are some disadvantages to this as well. These include groupthink and reinforcement of current views, as well as discouragement of new, outside views 
(Granovetter, 1974; Vidgen et al, 2007). Overall, it seems that most novel and effective research contributions are formed in cross-disciplinary groups rather than those that are cohesive and local. For instance, as Morlacchi et al. (2005) show, IMP group's core research group was formed across different nationalities, institutions and disciplines, and provided a strong push for a new research perspective in business research. These results are more in line with an alternative (yet complementary) network structural argument called "structural holes" (Burt, 1992, 2004). This argumentation suggests that actors can access especially valuable, non-redundant resources in networks when they occupy positions that span structural holes - i.e. connect networks that would otherwise be unconnected.

In summary, social network analysis of scientific communities can reveal structural and positional attributes that can be used in further analyses for several purposes. Our focus in this study is especially to analyse whether ISPIM community is formed around certain core countries and institutions or key authors. We also aim to find out what type of authors occupy central positions in the overall ISPIM network and how certain substructures are formed within this network. In addition, in interpreting the results, we will address qualitative considerations of the potential motivations and paths that lead to certain type positions and structures in the co-authorship network.

\section{Research Methodology}

\subsection{Research Design}

The goal of this study is to explicitly model and describe the structure of the ISPIM innovation management research community from the social network analysis point of view. Instead of citation and co-citation methods, which are more commonly used to evaluate scientific communities (e.g. Robinson and Adler, 1981, Cote et. al. 1991, Üsdiken and Pasadeos, 1995), we based our analysis on co-authorship ties, similarly to previous studies by Newman (2001, 2004), Morlacchi et. al. (2005) and Vidgen et. al. (2007). In our opinion, co-authorship is a key measure in accurately revealing the genuine collaborative relationship between researchers, in comparison to other methods such as citation and co-citation analyses. For instance, writing a scientific paper together requires significantly more hands-on collaboration when compared to more easily made citations. Furthermore, by applying bibliographic analysis, we identify who are the key authors and countries based on co-authorship relations and what kind of ties have been constructed among these actors.

In conducting the analysis on the network structure of the ISPIM community, we will utilise standard methodology and visualization tools of social network analysis, utilizing UCINET software (e.g. Wasserman and Faust, 1994; Borgatti et al., 1992). The adopted approach involves identification of the structure of the network, including the linkages between the authors and different types of actor roles in it (e.g. various centrality measures and roles for individual actors). We will also present exact descriptive statistics for the whole data, a set of top authors regarding centrality measures, as well as a visual analysis of the largest sub-components in the whole network. 


\subsection{Data Collection and Sample Selection}

In this study, we focus on the scientific community of ISPIM - an acronym for International Society for Professional Innovation Management. ISPIM originated from the initiatives of Professor Knut Holt from University of Trondheim at 1973 (for a detailed description of the conception of ISPIM, see Holt, 2006; ISPIM 2012). Prof. Holt organised a program called Needs Assessment and Information Behaviour (the NAIB Program). The objective of the program was to find tools and guidelines for the assessment of user needs in the product innovation process. The NAIB and related collaboration led eventually to the formal conception of ISPIM in Trondheim, Norway in June 1983. Due to increasing interest in innovation management in practice and academia, ISPIM has grown today as a popular forum for scientific and practitioner events across the globe. Currently ISPIM hosts two major scientific events per year (a conference in the Summer and a symposium at the end of the year). At the time of writing this study, it has 702 members from 62 countries.

ISPIM is an international scientific community in its pure sense, as it connects individual researchers unified by a common topic and interest (see e.g. Bourdieu, 2004). In the case of ISPIM, this topic innovation - Innovation can be defined as "a process of turning opportunity into new ideas and of putting these into widely used practice" (Tidd et al., 2005, 66) and innovation management as building and improving effective routines related to various aspects of innovation (ibid.). In addition to academics, throughout its history, ISPIM has also included strong participation from business practitioners and consultants. However, in this study we explicitly focus on academic papers and related co-authorship, in order to specifically investigate ISPIM as a scientific, scholarly community.

The data of our study is based on archival data of six ISPIM conference and symposium events between 2009 and 2011. The collected data includes information related to academic research publications, their authors, and the affiliations of the authors. The chosen scope has its potential advantages and disadvantages. The advantage is that focusing on the latest six events provides us with a picture of the recent state of the ISPIM innovation management community, and thus the focus is on the on-going collaboration within the network. The disadvantage is that some linkages which still may be active do not appear in our analysis. These issues should be kept in mind when interpreting the results.

The unit of analysis in this study is an ISPIM research paper with two or more authors. Following a bibliometric approach the following steps were conducted: Firstly, the reference list of all co-authored ISPIM publications was generated. Secondly, from each paper, author names, organizations, and countries were collected and doublechecked to ensure that each author was identified correctly. This process included also the identification of the possibility having different authors with same name as suggested by Newman (2001), and checking the authors who had possible changed their name as a result e.g. a marriage or a divorce during the given time period. Thirdly, co-authorship relationships between all authors were measured and weighted (i.e. counting how many co-authored papers authors/organizations/countries had with each other). Fourthly, this verified data was then sorted, analysed and visualised with the help of Excel, SPSS, Ucinet and Netdraw software packages. 


\subsection{Social network analysis as a research method}

In social settings, social network analysis has underlying features from social exchange theory, where actors are viewed as being interdependent on each other, and the interconnections of actors do represent exchange of knowledge or other otherwise relevant activity (Blau, 1964; Wassermann and Faust, 1994). Social network analysis, on the other hand, is also a specific systematic methodology to analyse informal and formal social networks with a certain methodology, measures and tools (e.g. Wasserman and Faust, 1994). Social network analysis is formally based on network theory and graph theory, which are focused on analysing symmetric or asymmetric ties that connect discrete objects and actors (such as individuals, groups or companies) together.

The fundamental difference in social network analysis over non-network-type of studies is that it includes relevant relational information beyond the attributes of individual actors, which helps to understand how the behaviour of individuals and communities is related to the social structures in which they are embedded. (Yan and Assimakopoulos, 2009). In this study, we adopt both theoretical and methodological approaches to social network analysis in investigating the co-authorship networks in a scientific community.

\subsection{Key Measures}

In social network analysis, there are numerous measures that can be used to measure centrality positioning of the nodes in a given network. A node refers here to any kind of actor within a network (e.g., an individual, a role, a company). Centrality measures help in determining the importance of a particular node in the network (Wassermann and Faust, 1994). Thus, in conducting the empirical analyses, we take the node's (here = authors or authors' countries) centrality positions as the unit of analysis. To indicate centrality of nodes, we utilise measures of degree centrality and betweenness centrality. We also measure the absolute co-authorship output from the study period for each node, which we call the collaboration intensity. These three measures are briefly described below.

Degree centrality (Freeman, 1979) is the most simple, most used and most easy-tointerpret measure of the node's network position. Degree centrality calculates how many direct connections each node has with other nodes in the network. Therefore, it directly shows how linked each node is to other nodes. A high degree centrality then indicates that the node has a central position in the network among other nodes (indicating e.g. a "hub" or otherwise relevant position). We also measure collaboration intensity, which is in principle the same measure as degree centrality, but which also takes into account if a certain co-authorship has been conducted multiple times (whereas in the degree centrality all unique co-authorship connections are counted only once). Thus, collaboration intensity can be interpreted as the total number of co-authorship connections in the measured period of time, not taking into account if these connections are to same or different authors.

Betweenness centrality (Freeman, 1979) departs from the above-mentioned measures in that it is used for investigating the structural position of a particular node between clusters of nodes in a network. Therefore it can be interpreted as measuring the nodes based on their position and role as a gatekeeper between two or more independent components. Such nodes may be in a structurally powerful position because they might 
be able to exploit their gatekeeper role for the purposes of knowledge and resource sharing between the separate parts of the network, for example.

To further facilitate the interpretation of the results, we will also conduct an analysis of network components. According to Hawe et. al. (2004), a component is a part of a network in which all authors are directly or indirectly connected by at least one connection. Thus, the component analysis will reveal those groups within the whole of the ISPIM network that are internally connected, but separate from each other.

\section{Results}

\subsection{A Descriptive Profile of ISPIM publications from 2009 to 2011}

In Table 1 we have presented a descriptive profile of the ISPIM conference and symposium publications based on the number of publications. Altogether, 789 ISPIM papers were published from 2009 to 2011. Of these, on average 184 were published from the annual conference and 79 from the annual symposium. This makes conferences over 2.3 times larger than symposiums when the number of publications is used as a metric.

Table 1. A Descriptive Profile of the number of ISPIM publications from 2009 to 2011

\begin{tabular}{|c|c|c|c|c|c|c|c|}
\hline \multirow[t]{2}{*}{ Event } & \multicolumn{3}{|c|}{ Conferences } & \multicolumn{3}{|c|}{ Symposium } & \multirow[b]{2}{*}{ Total } \\
\hline & $\begin{array}{r}2009 \\
\text { Vienn } \\
\mathrm{a} \\
\end{array}$ & $\begin{array}{r}2010 \\
\text { Bilbao }\end{array}$ & $\begin{array}{r}2011 \\
\text { Hamburg }\end{array}$ & $\begin{array}{l}2009 \\
\text { New } \\
\text { York }\end{array}$ & $\begin{array}{r}2010 \\
\text { Quebec }\end{array}$ & $\begin{array}{r}2011 \\
\text { Wellington }\end{array}$ & \\
\hline EU/Funded Project & 0 & 3 & 1 & 0 & 0 & 0 & 4 \\
\hline $\begin{array}{l}\text { Full Academic } \\
\text { Paper }\end{array}$ & 120 & 120 & 134 & 60 & 47 & 53 & 534 \\
\hline Funded Project & 0 & 0 & 0 & 0 & 0 & 1 & 1 \\
\hline $\begin{array}{l}\text { Practitioner } \\
\text { Presentation }\end{array}$ & 13 & 11 & 10 & 4 & 6 & 5 & 49 \\
\hline $\begin{array}{l}\text { Short Academic } \\
\text { Paper }\end{array}$ & 65 & 42 & 33 & 32 & 18 & 11 & 201 \\
\hline Total & 198 & 176 & 178 & 96 & 71 & 70 & 789 \\
\hline
\end{tabular}

According to the classification profile based on percentage shares in Table 2, about 2/3 of the published papers are full academic papers (percentage ranges from 61 to 76 per cent between events). The second largest category is short academic papers, which represent about $1 / 4$ share of the all publications. However, the variance between events is substantially larger compared to full papers, since the percentage share of the short papers ranges from 16 to 33 per cent. Compared to academic papers, the practitioner publications category share is significantly smaller and on average it only has around a 6 per cent share. Funded EU and other projects papers are only published randomly by ISPIM (less than 1 per cent of the all publications). 
Table 2. A Descriptive Profile of the percentage share of ISPIM publications from 2009 to 2011

\begin{tabular}{|c|c|c|c|c|c|c|c|}
\hline \multirow[t]{3}{*}{ Event } & \multicolumn{3}{|c|}{ Conferences } & \multicolumn{3}{|c|}{ Symposium } & \multirow{3}{*}{ Total } \\
\hline & 2009 & 2010 & 2011 & 2009 & 2010 & 2011 & \\
\hline & Vienna & Bilbao & Hamburg & $\begin{array}{l}\text { New } \\
\text { York }\end{array}$ & Quebec & Wellington & \\
\hline EU/Funded Project & $0 \%$ & $2 \%$ & $1 \%$ & $0 \%$ & $0 \%$ & $0 \%$ & $0.5 \%$ \\
\hline Full Academic Paper & $61 \%$ & $68 \%$ & $75 \%$ & $63 \%$ & $66 \%$ & $76 \%$ & $68 \%$ \\
\hline Funded Project & $0 \%$ & $0 \%$ & $0 \%$ & $0 \%$ & $0 \%$ & $1 \%$ & $0.1 \%$ \\
\hline Practitioner & $7 \%$ & $6 \%$ & $6 \%$ & $4 \%$ & $8 \%$ & $7 \%$ & $6 \%$ \\
\hline Presentation & & & & & & & \\
\hline $\begin{array}{l}\text { Short Academic } \\
\text { Paper }\end{array}$ & $33 \%$ & $24 \%$ & $19 \%$ & $33 \%$ & $25 \%$ & $16 \%$ & $25 \%$ \\
\hline
\end{tabular}

As a result, even if ISPIM events have participants from academic communities and practitioners such as industrialists, consultants and public sector actors, it appears that the majority of ISPIM publications are made by academics (or at least a large majority of publications are filed as academic papers).

Since in this study we were especially interested in evaluating co-authorship relationships, in Table 3 we have presented a crosstab for number of authors and publication type. It seems that project papers and practitioner presentations are typically written individually (i.e. all these publications had only one author) whereas writing a full or short scientific paper is more likely to be written in a small group (about 23 per cent of these publications had a single author). In general, the number of authors in ISPIM publication remains less than four (87 per cent of the publications had 3 or less authors). About 9 per cent of the papers have four authors, while five or six author papers have only 4 per cent share combined. Based on these results, the most interesting categories for our further analysis are full and short academic papers, since only those fulfil our requirement for unit of analysis (i.e. those include co-authored publications) and representing the majority of publications.

Table 3. A crosstab of the author count and publication type by number of publications and percentage share

\begin{tabular}{lrrrrrrr}
\hline $\begin{array}{l}\text { Author } \\
\text { count }\end{array}$ & $\begin{array}{r}\text { EU } \\
\text { Project or } \\
\text { Funded } \\
\text { Project }\end{array}$ & $\begin{array}{r}\text { Full } \\
\text { Academic } \\
\text { Paper }\end{array}$ & $\begin{array}{r}\text { Funded } \\
\text { Project }\end{array}$ & $\begin{array}{r}\text { Practitioner } \\
\text { Present. }\end{array}$ & $\begin{array}{r}\text { Short } \\
\text { Academic } \\
\text { Paper }\end{array}$ & $\begin{array}{r}\text { Total } \\
\text { Total } \\
\text { cum. } \\
\%\end{array}$ \\
\hline 1 & $4(100 \%)$ & $118(22 \%)$ & $1(100 \%)$ & $49(100 \%)$ & $49(24 \%)$ & $221(28 \%)$ & 28 \\
2 & 0 & $191(36 \%)$ & 0 & 0 & $75(37 \%)$ & $266(34 \%)$ & 62 \\
3 & 0 & $156(29 \%)$ & 0 & 0 & $47(23 \%)$ & $203(26 \%)$ & 87 \\
4 & 0 & $50(9 \%)$ & 0 & 0 & $21(10 \%)$ & $71(9 \%)$ & 96 \\
5 & 0 & $9(2 \%)$ & 0 & 0 & $6(3 \%)$ & $15(2 \%)$ & 98 \\
6 & 0 & $10(2 \%)$ & 0 & 0 & $3(1 \%)$ & $13(2 \%)$ & 100 \\
Total & 4 & 534 & 1 & 49 & 201 & 789 & $100 \%$ \\
Total\% & $0.5 \%$ & $67.7 \%$ & $0.1 \%$ & $6.2 \%$ & $25.5 \%$ & & \\
\hline
\end{tabular}

\subsection{Country level analysis of the ISPIM publications}

In order to understand more about the structure of ISPIM multi-authored publications, a country analysis was conducted. In Table 4 we have presented a crosstab for the number of authors and number of countries per publication. 
Table 4. A crosstab of the author count and number of countries in one publication

\begin{tabular}{lllll}
\hline $\begin{array}{l}\text { Author } \\
\text { count }\end{array}$ & One county & Two countries & Three countries & Total \\
\hline 1 & $221(28 \%)$ & - & - & $221(28 \%)$ \\
2 & $253(32 \%)$ & $13(1.6 \%)$ & - & $266(34 \%)$ \\
3 & $171(22 \%)$ & $32(4.1 \%)$ & - & $203(26 \%)$ \\
4 & $50(6 \%)$ & $17(2.2 \%)$ & $4(0.5 \%)$ & $71(9 \%)$ \\
5 & $11(1 \%)$ & $3(0.4 \%)$ & $1(0.1 \%)$ & $15(2 \%)$ \\
6 & $9(1 \%)$ & $3(0.4 \%)$ & $1(0.1 \%)$ & $13(2 \%)$ \\
Total & $715(90.6 \%)$ & $68(8.6 \%)$ & $6(0.8 \%)$ & $789(100 \%)$ \\
\hline
\end{tabular}

It appeared that 715 out of 789 publications (91 per cent) are made by authors from the same country. Occasionally authors of individual ISPIM publication come from two different countries (68 publications had authors from two countries resulting 9 per cent share) and only randomly from three different countries (in all 6 publications, resulting less than 1 per cent share). The most common setup for international collaboration is three authors from two different countries (4.1 per cent).

From 2009 to 2011 ISPIM publications were made by 1250 authors from 55 different countries. According to Table 5 Germany and Finland are clearly the leading countries regarding number of authors in the ISPIM community. Altogether there were 191 German and 179 Finnish authors who in all represent nearly 30 percentage share of all authors. The third biggest country was Spain with 91 authors and fourth was United Kingdom (UK) with 69 authors.

Table 5. Number of authors per country: TOP 20 countries

\begin{tabular}{|c|c|c|c|c|c|c|c|}
\hline Rank & Country & $\begin{array}{l}\text { Author } \\
\text { count }\end{array}$ & $\begin{array}{l}\text { Author } \\
\%\end{array}$ & Rank & Country & $\begin{array}{l}\text { Author } \\
\text { count }\end{array}$ & $\begin{array}{l}\text { Author } \\
\%\end{array}$ \\
\hline 1 & Germany & 191 & 15,3 & 11 & Brazil & 33 & $2,6 \%$ \\
\hline 2 & Finland & 179 & 14,3 & 12 & Belgium & 31 & $2,5 \%$ \\
\hline 3 & Spain & 91 & 7,3 & 13 & USA & 30 & $2,4 \%$ \\
\hline 4 & UK & 69 & 5,5 & 14 & Australia & 29 & $2,3 \%$ \\
\hline 5 & Taiwan & 57 & 4,6 & 15 & Switzerland & 29 & $2,3 \%$ \\
\hline 6 & Austria & 47 & 3,8 & 16 & Canada & 27 & $2,2 \%$ \\
\hline 7 & Sweden & 45 & 3,6 & 17 & New Zealand & 27 & $2,2 \%$ \\
\hline 8 & Netherlands & 41 & 3,3 & 18 & Italy & 25 & $2,0 \%$ \\
\hline 9 & Japan & 39 & 3,1 & 19 & South Korea & 23 & $1,8 \%$ \\
\hline 10 & France & 36 & 2,9 & 20 & Luxembourg & 17 & $1,4 \%$ \\
\hline
\end{tabular}

In order to evaluate in more detail what kinds of relationships are occurring between countries, an ego analysis at the country level was conducted with the help of Ucinet and Netdraw software packages (Table 6 on the next page). Thus, instead of using individual authors as a measure, in this analysis we converted each author to represent their home country. In the case of degree centrality measure, which measures the number of direct ties that an actor has (Freeman, 1979), the simultaneous inter-country co-authorship occurrences were calculated only once to show the actual amount of diversity of such activities. However, the simultaneous occurrences were taken into account in the case of collaboration intensity measure, helping to better show the volume of collaboration.

33 out of 55 countries (60 per cent) had collaborated internationally. To facilitate the understanding of the complex phenomenon of multi-actor social networks, we also visualised country level ISPIM co-author network relationships in Figure 1 (see next 
page). In order to visualise the differences between countries more clearly, we also weighted some of the key measures in Figure 1. First, the lines between countries are weighted according to the number of co-authorships. The stronger the black line is, the more co-publications countries have made together. Here, if two authors had written more than one publication, their contribution was taken into account multiple times.

As shown in Figure 1, the line between Finland and Russia is the strongest (they have 27 connections). For example in the case of 1) USA and Canada and 2) Austria and Australia the line is thinnest since those countries have only 1 connection with each other. When all connections are included to count (i.e. collaboration intensity measure), Finland is the leading country with 72 connections, Germany second with 54 connections and UK third with 33 connections. Other major players are Netherlands (32 connections), Russia (27), USA (24) and Belgium (20). Rest of the countries results are presented in next page Table 6 collaboration intensity column. 
Table 6. ISPIM publication network- Ego analysis at country level from Vienna 2009 to New Zealand 2011

\begin{tabular}{|c|c|c|c|c|c|c|c|c|}
\hline \multirow[b]{2}{*}{1} & \multicolumn{2}{|c|}{ Betweenness centrality } & \multicolumn{3}{|c|}{ Degree centrality } & \multicolumn{3}{|c|}{ Collaboration intensity } \\
\hline & Germany & 200,6 & 1 & UK & 15 & 1 & Finland & 72 \\
\hline 2 & UK & 151,1 & 2 & Germany & 14 & 2 & Germany & 54 \\
\hline 3 & Finland & 105,3 & 3 & Finland & 12 & 3 & UK & 33 \\
\hline 4 & Spain & 61,0 & 4 & France & 10 & 4 & Netherlands & 32 \\
\hline 5 & USA & 51,1 & 5 & Netherlands & 8 & 5 & Russia & 27 \\
\hline 6 & France & 49,5 & 6 & USA & 8 & 6 & USA & 24 \\
\hline 7 & Netherlands & 42,0 & 7 & Austria & 7 & 7 & Belgium & 20 \\
\hline 8 & Austria & 33,1 & 8 & Belgium & 7 & 8 & Austria & 19 \\
\hline 9 & India & 31,0 & 9 & New Zealand & 7 & 9 & France & 18 \\
\hline 10 & Switzerland & 31,0 & 10 & Portugal & 5 & 10 & New Zealand & 13 \\
\hline 11 & Belgium & 27,4 & 11 & Canada & 4 & 11 & India & 11 \\
\hline 12 & New Zealand & 16,9 & 12 & India & 4 & 12 & Switzerland & 9 \\
\hline 13 & Portugal & 14,5 & 13 & Singapore & 4 & 13 & Singapore & 9 \\
\hline 14 & Canada & 3,4 & 14 & Spain & 4 & 14 & Spain & 9 \\
\hline 15 & Japan & 1,9 & 15 & Switzerland & 4 & 15 & Portugal & 8 \\
\hline 16 & Czech Rep. & 0,3 & 16 & Australia & 3 & 16 & Canada & 8 \\
\hline 17 & Australia & 0 & 17 & Czech Rep. & 3 & 17 & Israel & 8 \\
\hline 17 & China & 0 & 18 & Japan & 3 & 18 & Australia & 5 \\
\hline 17 & Colombia & 0 & 19 & Luxembourg & 3 & 19 & South Korea & 4 \\
\hline 17 & Croatia & 0 & 20 & Ireland & 3 & 20 & Czech Rep. & 4 \\
\hline 17 & Israel & 0 & 21 & South Korea & 3 & 21 & Ireland & 4 \\
\hline 17 & Italy & 0 & 22 & China & 2 & 22 & Japan & 4 \\
\hline 17 & Lithuania & 0 & 23 & Israel & 2 & 23 & Taiwan & 3 \\
\hline 17 & Luxembourg & 0 & 24 & Italy & 2 & 24 & Colombia & 3 \\
\hline 17 & Mexico & 0 & 25 & Russia & 2 & 25 & Luxembourg & 3 \\
\hline 17 & Nigeria & 0 & 26 & Sweden & 2 & 26 & Lithuania & 3 \\
\hline 17 & Ireland & 0 & 27 & Colombia & 1 & 27 & Croatia & 2 \\
\hline 17 & Russia & 0 & 27 & Croatia & 1 & 28 & Mexico & 2 \\
\hline 17 & Singapore & 0 & 27 & Lithuania & 1 & 29 & China & 2 \\
\hline 17 & South Korea & 0 & 27 & Mexico & 1 & 30 & Italy & 2 \\
\hline 17 & Sweden & 0 & 27 & Nigeria & 1 & 31 & Turkey & 2 \\
\hline 17 & Taiwan & 0 & 27 & Taiwan & 1 & 32 & Sweden & 2 \\
\hline 17 & Turkey & 0 & 27 & Turkey & 1 & 33 & Nigeria & 1 \\
\hline
\end{tabular}

Figure 1. ISPIM co-author network at country level between 2009 and 2011 


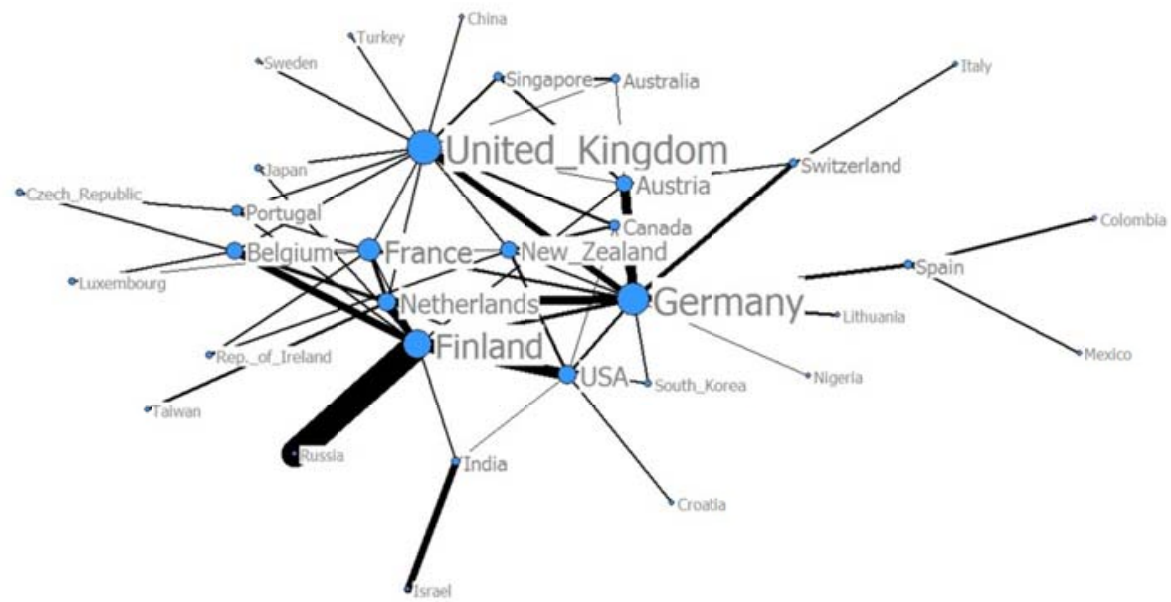

Second, the size of the circle in front the country name is weighed on the basis on the number of individual connections (i.e. degree centrality measure column). The bigger the circle is, the more individual connections the country has. United Kingdom circle is the biggest with 15 individual connections, Germany the second biggest with 14 connections and Finland third largest with 12 connections. Runner-ups are France with (10 connections), Netherlands (8), and USA (8), Austria (7) and New Zealand (7). In Table 6 degree centrality column we have presented the rest of the country-specific results.

As we could assume based on the simple descriptive statistics, the countries which were leading in the number of co-authored papers, have also leading and central positions in the network analysis. Following in-depth analysis reveals the underlying reasons what kind of collaboration each county is doing with other countries. Germany with largest number of authors (191) has the most central position in terms of betweenness of the ISPIM country network (betweenness centrality value in Table 6 is 200.6). Interestingly, the second largest author country Finland (179 authors) is not second but the third most central country within ISPIM network (betweenness centrality $=105.3$ ). Authors from United Kingdom (betweenness centrality $=151.1$ ) are a bit more diversely connected actors in the network than Finland resulting second most central position for them. Overall, in our opinion these three countries (Germany, Finland and United Kingdom) are forming the backbone of the ISPIM international network in terms of both centrality and volume of co-authorship connections.

In order to evaluate the relative internationalisation interest and internationalisation strategy among different countries, internationalisation ratio was defined by dividing degree centrality and number of authors. Since this measure does not take into account multiple publications between authors, internationalisation volume ratio was defined by dividing collaboration intensity with the number of authors. We named this measure as internationalisation volume ratio. Results are shown in Table 7. 
Table 7. Internationalisation ratio TOP 20 countries

\begin{tabular}{|c|c|c|c|c|c|c|c|c|c|}
\hline & Country & & $\begin{array}{l}\text { ee / } \\
\text { ber of } \\
\text { ors }\end{array}$ & $\begin{array}{l}\text { Int. } \\
\text { ratio }\end{array}$ & & Country & $\begin{array}{l}\text { Int } \\
\text { Nu } \\
\text { aut }\end{array}$ & $\begin{array}{l}\text { isity. / } \\
\text { ber of } \\
\text { ors }\end{array}$ & $\begin{array}{l}\text { Int. } \\
\text { vol. } \\
\text { ratio }\end{array}$ \\
\hline 1 & France & 10 & 36 & 0,28 & 1 & USA & 24 & 30 & 0,80 \\
\hline 2 & USA & 8 & 30 & 0,27 & 2 & Netherlands & 32 & 41 & 0,78 \\
\hline 3 & New Zealand & 7 & 27 & 0,26 & 3 & Belgium & 20 & 31 & 0,65 \\
\hline 4 & Belgium & 7 & 31 & 0,23 & 4 & France & 18 & 36 & 0,50 \\
\hline 5 & UK & 15 & 69 & 0,22 & 5 & New Zealand & 13 & 27 & 0,48 \\
\hline 6 & Netherland & 8 & 41 & 0,20 & 6 & UK & 33 & 69 & 0,48 \\
\hline 7 & Luxembourg & 3 & 17 & 0,18 & 7 & Austria & 19 & 47 & 0,40 \\
\hline 8 & Austria & 7 & 47 & 0,15 & 8 & Finland & 72 & 179 & 0,40 \\
\hline 9 & Canada & 4 & 27 & 0,15 & 9 & Switzerland & 9 & 29 & 0,31 \\
\hline 10 & Switzerland & 4 & 29 & 0,14 & 10 & Canada & 8 & 27 & 0,30 \\
\hline 11 & South Korea & 3 & 23 & 0,13 & 11 & Germany & 54 & 191 & 0,28 \\
\hline 12 & Australia & 3 & 29 & 0,10 & 12 & Luxembourg & 3 & 17 & 0,18 \\
\hline 13 & Italy & 2 & 25 & 0,08 & 13 & South Korea & 4 & 23 & 0,17 \\
\hline 14 & Japan & 3 & 39 & 0,08 & 14 & Australia & 5 & 29 & 0,17 \\
\hline 15 & Germany & 14 & 191 & 0,07 & 15 & Japan & 4 & 39 & 0,10 \\
\hline 16 & Finland & 12 & 179 & 0,07 & 16 & Spain & 9 & 91 & 0,10 \\
\hline 17 & Sweden & 2 & 45 & 0,04 & 17 & Italy & 2 & 25 & 0,08 \\
\hline 18 & Spain & 4 & 91 & 0,04 & 18 & Taiwan & 3 & 57 & 0,05 \\
\hline 19 & Taiwan & 1 & 57 & 0,02 & 19 & Sweden & 2 & 45 & 0,04 \\
\hline 20 & Brazil & 0 & 33 & 0,00 & 20 & Brazil & 0 & 33 & 0,00 \\
\hline
\end{tabular}

Interestingly, those from ISPIM backbone countries like United Kingdom, which in all had only 69 different authors compared to German's 191 and Finland's 179 authors, has clearly been more aggressive international collaborator. United Kingdom internationalisation ratio was 0.22 compared to German's and Finland's 0.07. In the case of volume based internationalisation comparison United Kingdom is clearly beating Germany (0.48 vs. 0.28) while United Kingdom and Finland are performing almost evenly (0.48 vs. 0.40$)$. This indicates that Finland is favouring more intensive international relationships in comparison to two other major ISPIM actors. Finland's position from this perceptive can be partially explained by strong collaboration between three Russian researchers from St. Petersburg State University and five researchers from Lappeenranta University of Technology in Finland.

When other TOP 10 high number author countries are evaluated in more detail, it appeared that Taiwan and Sweden took an opposite direction compared to the United Kingdom and ended up at the bottom of the TOP 20 internationalisation ratio ranking. It appeared that Sweden-based authors had only one internationally co-authored publication, which was actually made by a Swedish author visiting the UK at the time of publication. Furthermore, in the case of Taiwan, only one author out of 26 had collaborated three times with the same Dutch author. Moreover, authors from the USA seem to value international collaboration within the ISPIM community since they have the second best internationalisation ratio value (0.27) and the best internationalisation volume ratio ( 0.80$)$. There are definitely different strategies regarding internationalisation among authors from different countries participating in the ISPIM community. 


\subsection{Component analysis}

In order to understand the ISPIM network structure more deeply, we conducted a component analysis which reveals the separate co-authorship groups within the ISPIM network. In Figure 2, we have visualised the ISPIM co-author network on the basis of component structure. The main component is highlighted in black and all the other remaining 284 components are coloured grey.

Figure 2. ISPIM co-author network component structure where the main component is visualised in black)

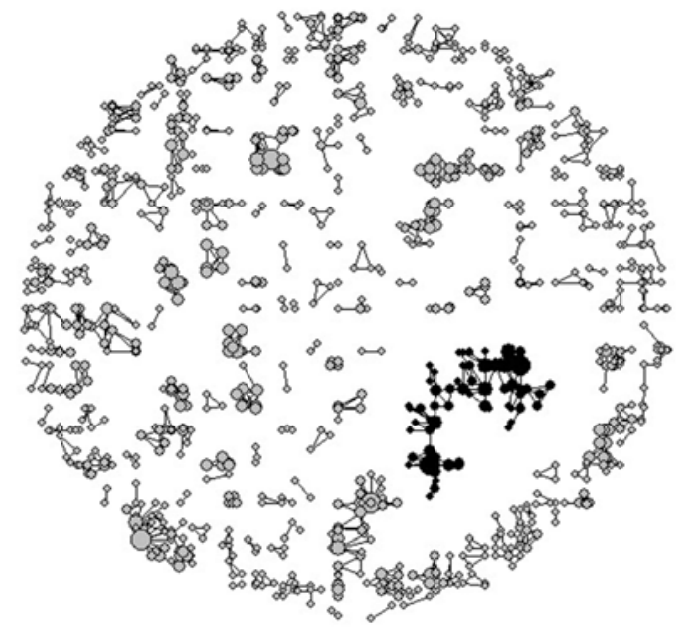

Altogether the ISPIM network included 1095 different authors who have co-authored one or more ISPIM publication. As Figure 2 illustrates, the majority of components are very small. In Table 8 we have named the major components on the basis of component members and their home country and have presented descriptive statistics regarding the component structure.

Table 8. Components descriptive statistics

\begin{tabular}{llllllll}
\hline & Name & Size & \% & Rank & Name & Size & \% \\
\hline 1 & Finland led by multiple key authors & 82 & 7,5 & 11 & 2 comp. & 8 & 0.7 \\
2 & Germany led by JLeker & 20 & 1,8 & 12 & 6 comp. & 7 & 0.6 \\
3 & VTT Finland led by 3 key authors & 18 & 1,6 & 13 & 16 comp. & 6 & 0.5 \\
4 & Luxemburg led by ALMention & 17 & 1,5 & 14 & 22 comp. & 5 & 0.5 \\
5 & Sweden led by BBergvall Kårenborn & 16 & 1,5 & 15 & 34 comp. & 4 & 0.4 \\
6 & UK led by JBessant & 15 & 1,4 & 16 & 86 comp. & 3 & 0.3 \\
7 & Switzerland led by RBooutellier & 14 & 1,3 & 17 & 108 comp. & 2 & 0.2 \\
8 & Taiwan led by 3 key authors & 13 & 1,2 & & & & \\
9 & VTT Finland Oulu led by & 10 & 0,9 & & & & \\
& MPikkarainen & & & & & & \\
10 & 2 components & 9 & 0,8 & & &
\end{tabular}

According to our component analysis, 108 components (38 per cent of all components) include only two authors, 86 components (30 per cent) include three authors, 34 components (12 per cent) include four authors and 22 components (8 per cent) include five authors. As a summary, 2/3 of the co-authored publications are made by ISPIM sub networks which include 5 or fewer authors. 
The main component (i.e. largest component), which was visualised in black in Figure 2, includes 82 authors who mainly come from Finland. The detailed structure of the main component and the names of the authors and their relationships are presented on the next page in Figure 3 and followed by Table 9 presenting an ego analysis of main individual ISPIM co-authors. Besides the author's name, a country code was added to help us identify what kind of role each country has in the key author listing. In Table 9, depending on the variable, 29 to 37 individual author names are presented in order to keep the table in one page size. Moreover, the eight largest major components are also visualised in Appendix 1 and Appendix 2 Figures 1 to 4.

The results show, combined with the visual examination of Figure 3 and the appendices, that certain authors are clearly situated in central positions in their networks. Further examination also shows some variation between the measures. Firstly, the results clearly show that the authors situated high in betweenness centrality are those who combine and bridge two major clusters within the whole main component. Secondly, the main component involves several authors that have co-authored a lot within their network, and have also collaborated with a diverse network of authors. Interestingly, however, some authors outside the main component score notably high in the degree centrality. This result shows that such authors collaborate quite diversely in their particular areas within the whole ISPIM network. 
Figure 3. Main component visualisation

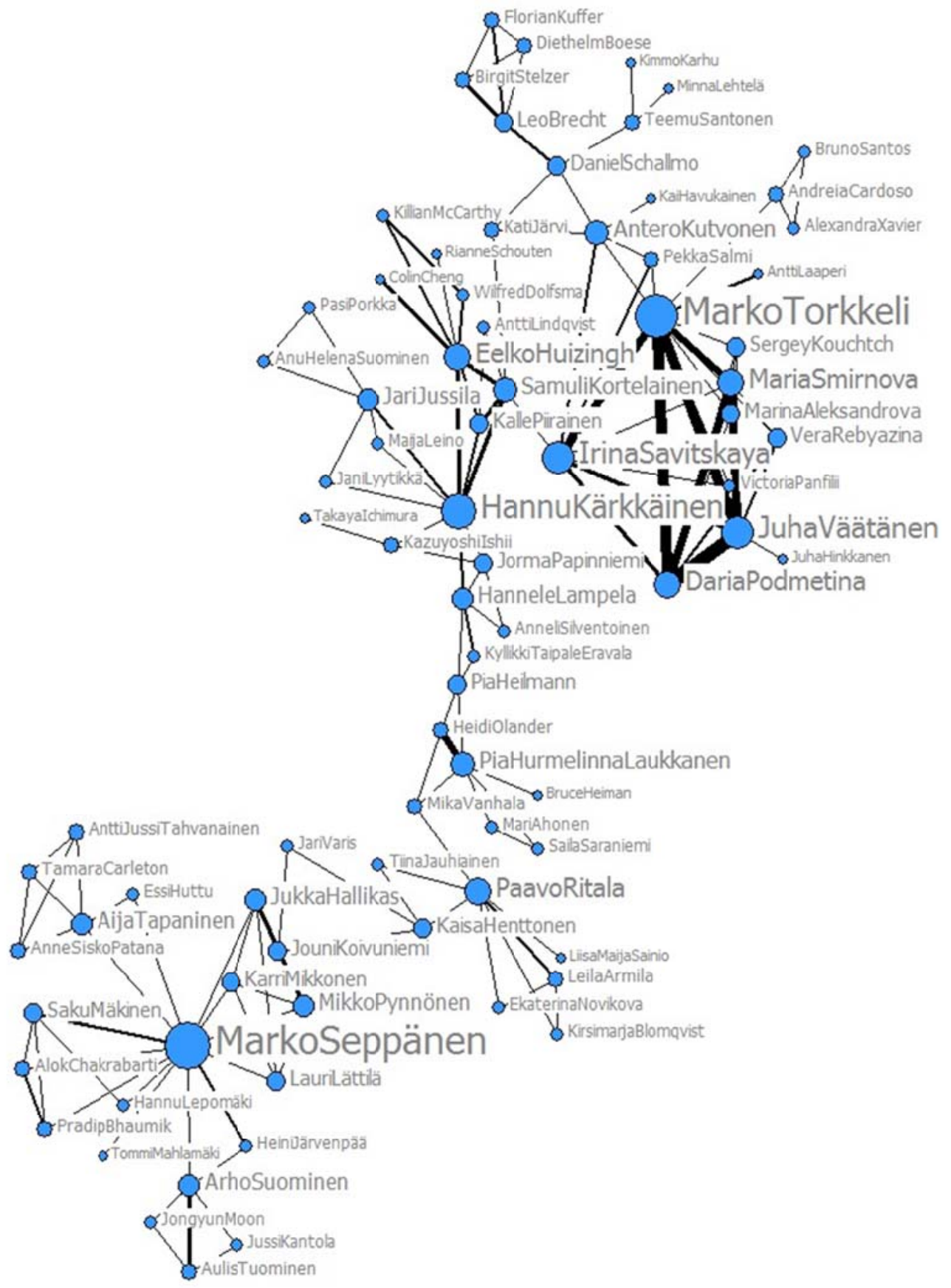


Table 9. ISPIM publication network - Ego analysis 1 of 1097 authors from Vienna 2009 to New Zealand 2011

\begin{tabular}{|c|c|c|c|c|c|c|c|c|}
\hline \multicolumn{3}{|c|}{ Betweenness centrality } & \multicolumn{3}{|c|}{ Degree centrality } & \multicolumn{3}{|c|}{ Collaboration intensity } \\
\hline 1 & HKärkkäinen FIN & 1847 & 1 & BBergvall-K... S & 15 & 1 & MTorkkeli FIN & 39 \\
\hline 2 & HLampela FIN & 1648 & 2 & JLeker GER & 13 & 2 & JVäätänen FIN & 35 \\
\hline 3 & PHeilmann FIN & 1610 & 3 & JBessant UK & 13 & 3 & DPodmetina FIN & 34 \\
\hline 4 & PRitala FIN & 1584 & 4 & MSeppänen FIN & 13 & 4 & MSmirnova RUS & 23 \\
\hline 5 & MVanhala FIN & 1508 & 5 & MTorkkeli FIN & 12 & 5 & JLeker GER & 21 \\
\hline 6 & SKortelainen FIN & 1459 & 6 & JPaasi FIN & 12 & 6 & ISavitskaya FIN & 20 \\
\hline 7 & KHenttonen FIN & 1298 & 7 & KValkokari FIN & 12 & 7 & JPaasi FIN & 20 \\
\hline 8 & JKoivuniemi FIN & 1220 & 8 & MPikkarainen FIN & 10 & 8 & KValkokari FIN & 19 \\
\hline 9 & MSeppänen FIN & 1070 & 9 & HKärkkäinen FIN & 9 & 9 & BBergvall-K... S & 18 \\
\hline 10 & PHurmelinna... FIN & 941 & 10 & ALMention $L$ & 8 & 10 & EHuizingh $N L$ & 16 \\
\hline 11 & ISavitskaya FIN & 873 & 11 & GSchuh GER & 8 & 11 & HKärkkäinen FIN & 16 \\
\hline 12 & HOlander FIN & 705 & 12 & ISavitskaya FIN & 8 & 12 & TLuoma FIN & 15 \\
\hline 13 & MPynnönen FIN & 558 & 13 & KLChi RC & 8 & 13 & MSeppänen FIN & 15 \\
\hline 14 & JHallikas FIN & 558 & 14 & MKTsai $R C$ & 8 & 14 & FcMiralles $E$ & 14 \\
\hline 15 & DSchallmo GER & 530 & 15 & TLuoma FIN & 8 & 15 & MMartinez..E & 13 \\
\hline 16 & KJärvi FIN & 504 & 16 & JVäätänen FIN & 8 & 16 & JBessant UK & 13 \\
\hline 17 & MTorkkeli FIN & 425 & 17 & DPodmetina FIN & 7 & 17 & SKortelainen FIN & 12 \\
\hline 18 & EHuizingh $N L$ & 313 & 18 & EHuizingh $N L$ & 7 & 18 & DChiaroni $I$ & 11 \\
\hline 19 & ASuominen FIN & 235 & 19 & MSmirnova RUS & 7 & 19 & FFrattini $I$ & 11 \\
\hline 20 & ATapaninen FIN & 234 & 20 & PRitala FIN & 7 & 20 & TMeristö FIN & 11 \\
\hline 21 & LBrecht GER & 234 & 21 & RBoutellier $\mathrm{CH}$ & 7 & 21 & JLaitinen FIN & 11 \\
\hline 22 & AKutvonen FIN & 213 & 22 & W-Chung $R C$ & 7 & 22 & GSchuh GER & 11 \\
\hline 23 & TSantonen FIN & 159 & 23 & AÖhrwall... S & 6 & 23 & MPikkarainen FIN & 10 \\
\hline 24 & JJussila FIN & 159 & 24 & AKutvonen FIN & 6 & 24 & PHurmelinna...FIN & 10 \\
\hline 25 & ACardoso $P$ & 158 & 25 & FMTseng $R C$ & 6 & 25 & K-LChi $R C$ & 9 \\
\hline 26 & JLeker GER & 130 & 26 & FReymann GER & 6 & 26 & HTuohimaa FIN & 9 \\
\hline 27 & JVäätänen FIN & 124 & 27 & FMiralles $E$ & 6 & 27 & MGomez Ji...E & 9 \\
\hline 28 & ALMention $L$ & 93 & 28 & JLSolleiro $M E X$ & 6 & 28 & RGarcia Esc...E & 9 \\
\hline 29 & KIshii $J$ & 80 & 29 & KSumikura $J$ & 6 & 29 & M-KTsai $R C$ & 9 \\
\hline 30 & CSCurran GER & 78 & 30 & OOmta $N L$ & 6 & 30 & 12 authors & 8 \\
\hline 31 & JBessant UK & 77 & 31 & PHurmelinna...FIN & 6 & 31 & 16 authors & 7 \\
\hline 32 & BBergvall-K...S & 77 & 32 & SKortelainen FIN & 6 & 32 & 38 authors & 6 \\
\hline 33 & KValkokari FIN & 71 & 33 & 96 authors & 5 & 33 & 84 authors & 5 \\
\hline 34 & ARousseau $L$ & 60 & 34 & 76 authors & 4 & 34 & 77 authors & 4 \\
\hline 35 & JPapinniemi FIN & 60 & 35 & 196 authors & 3 & 35 & 185 authors & 3 \\
\hline 36 & PJBarlatier $\mathrm{CH}$ & 59 & & 395 authors & 2 & 36 & 364 authors & 2 \\
\hline 37 & RBoutellier $\mathrm{CH}$ & 52 & & 300 authors & 1 & & 290 authors & 1 \\
\hline
\end{tabular}

NOTE: Some of the surnames have been shortened due to the space limitation. After each author, we have presented their home country as following country codes: 1) Finland = FIN, 2) Germany = GER, 3) Italy = I, 4) Japan = J, 5) Luxemburg = L, 6) Mexico = MEX, 7) Netherlands = NL, 8) Portugal $=$ P, 9) Russia $=$ RUS, 10) Spain = E, 11) Sweden = S, 12) Switzerland = CH, 13) Taiwan $=\mathrm{RC}$ and 14) United Kingdom $=\mathrm{UK}$.

\subsection{Ego analysis of individual ISPIM co-authors}

In general, in looking at country-specific affiliations, authors from Finland are clearly leading in each category. In the case of the Betweenness centrality measure, the first 14 authors are from Finland and in all 24 out of 37 authors are Finnish (i.e. 65 per cent). Finland is also performing well in the case of degree (14 out of 32 authors i.e. 44 per cent) and collaboration intensity (15 out of 29 authors i.e. 52 per cent) measure listings. 
The second most important country is Germany with significantly less performance (4 authors in the case of Betweenness, 3 authors in degree centrality and 2 authors in collaboration intensity). Other countries have more mixed and less significant presence regarding our key measure.

The most diversely connected (in terms of degree centrality) Finnish actors in the main component are Marko Seppänen from Tampere University of Technology with 13 connections and Marko Torkkeli from Lappeenranta University of Technology with 12 connections. As stated in the component analysis section, there are multiple authors outside the main component, who have notably high degree centrality. Among these actors are JPaasi (12 connections), KValkokari (12) and MPikkarainen (10). Interestingly JPaasi and KValkokari belong on a different component than MPikkarainen even if they belong to the same organization (VTT). However, the first two are from the city of Tampere and the latter is from Oulu. Geographical distance between these cities is nearly 500 kilometres. This makes intensive research collaboration more difficult compared to a neighbouring colleague. Other interesting and highly connected authors are the top ranking Birgitta Bergvall-Kåreborn (15 connections) from Luleå University of Technology (Sweden), Jens Leker (13 connections) from University of Muenster (Germany) and John Bessant (13 connections) from University of Exeter (United Kingdom). Detailed analysis of their connection reveal opposite strategies: 1) domestic and 2) international collaboration. Bergvall-Kåreborn has only Swedish connections and Leker has one international connection. On the contrary, 6 out of 13 connections in the case of John Bessant are international. These results are understandable based on the high share of single country publications in the overall data (91 per cent), but as the examples show, there is variation between the authors in this regard.

When collaboration intensity results are evaluated, it again reveals a strong Finnish presence. Widely-connected (12 different connections) Marko Torkkeli from Lappeenranta University of Technology is leading the collaboration intensity ranking with 39 hits, followed by his colleagues Juha Väätänen (35), Daria Podmetina (34) and sixth-ranked Irina Savitskaya (20). Interestingly, their high ranking in collaboration intensity can be partially explained especially by extensive collaboration with Russian author Maria Smirnova (23) from St. Petersburg State University. Clearly their international strategy has been multi-authored studies within a tight research group. This is somewhat different to John Bessant's multi author approach, for instance, where coauthorships have typically been conducted with different partners in each publication event. Surprisingly, geographical distance (in terms of research collaboration and research group formation tightness) can be offered as a partial explanation also in the case of Lappeenranta University of Technology and St. Petersburg State University collaboration in general. Even if Lappeenranta and St. Petersburg cities are located in different countries, they are actually only 180 kilometres from each other. It is also known that Lappeenranta University of Technology has a strategic focus on the Russian market, which may explain some of the intensity of the collaboration.

At the moment, the most central actor in terms of betweenness centrality in the ISPIM co-author network is Hannu Kärkkäinen from Tampere University of Technology, Finland. His betweenness centrality value is 1847. Based on the visual analysis, he has the most mixed strategy among the high performing authors in ISPIM network. He has strong collaboration with authors from his home university, authors from Lappeenranta University of Technology and some international connections. This mixture of diverse, yet connected partners, makes him an important gate-keeper within the ISPIM 
community. Several other authors also show up particularly highly in betweenness centrality, due to their unique position between various highly connected co-authorship clusters in the main component. These authors represent mainly Lappeenranta University of Technology, Finland (authors ranked in places 2-8 in betweenness centrality, Table 9).

To summarise our findings, it seems that there are multiple strategies to become a high-performing ISPIM community member, including: 1) strong domestic collaboration with close geographical distance actors, 2) widespread one-time international collaboration with multiple authors, 3) tight international collaboration with small, but long-term research groups and 4) mixture strategy which combines multiple approaches.

\section{Discussion and implications}

In this study, we have conducted a co-authorship-based social network analysis of the ISPIM innovation management community during the years 2009-2011. The results add to our understanding of how scientific networks are formed in general, and especially in the field of innovation management. By analysing co-authorship networks of ISPIM, this paper is the first attempt to understand the structure of this particular community, and can thus reveal interesting implications, as well as future research possibilities.

\subsection{Theoretical implications}

Overall, the results reveal the network structure in the co-authorship network, which shows that the ISPIM network is constructed from multiple sub-networks with one or several key actors in a central network positions, and from a large number of isolated coauthorship pairs or groups. Thus, the network, as a whole, does not follow an intuitive core/periphery or a "small world" structure (Barabási et al., 2002; Borgatti and Everett, 1999), where in the centre, there is a dense and tightly connected network of key actors. Rather, our results reveal a more scattered picture where the research collaboration within the ISPIM community is quite clustered and those clusters are based mostly on the country or the institution of authors'.

Our results are in line with the embeddedness (see e.g. Uzzi, 1996; Kilduff and Brass, 2010) and homophily (see e.g. McPherson et al., 2001) arguments in showing that scholars mostly collaborate with their existing networks and similar alters. This is shown in the concentration of co-authorship mainly in local institutional or geographical clusters around central or hub actors. For an actor in a central position in this type of network, the benefits may include a clearly manageable collective network where norms are easy to enforce and hold over time (Coleman, 1990; Granovetter, 2005). These issues are likely to be beneficial for the purposes of building long term research programs and research groups over well-specified topics. For instance, $\mathrm{PhD}$ students are likely to collaborate with their professors and other senior members of existing research groups, providing them a certain level of certainty and continuity during the $\mathrm{PhD}$ process. Thus, our results quite strongly support the notion that institutions and organizations matter in the formation of scientific communities (e.g Qin, 1994, Gazni et. al. 2012). It could also be argued that such scattered network with many sub-structures is a natural setting for broadly defined and multi-disciplinary field of innovation management, where new perspectives are often introduced and new scholars join in as new participants. 
There are also variations to this, however, in that we found several authors that were connected widely across different sub-groups or with otherwise distant actors. Such positions that bridge structural holes (see e.g. Burt, 1992) can be viewed as beneficial since they allow for creation and integration of complex knowledge effectively (Reagans and McEvily, 2002; Burt, 2004). Indeed, it has been suggested that solving complex problems requires especially trans-disciplinary knowledge integration (Stokols, 2006; Pohl and Hirsch Hadorn, 2007). Thus, for a scholar aiming for novel contributions, this perspective could be more prominent, since it allows for connection of distant actors with low level of redundancy (Burt, 1992), and therefore allowing to connect to knowledge that could leads to new insights.

We suggest that both of the above-mentioned findings for structural positions of key authors - collective and structural-hole spanning ones - provide important implications for the formation and existence of scientific communities. In fact, based on the results, it seems that the combination of these two co-authorship drivers leads to powerful clusters within a scientific community. In our study the main component is a typical example, where institutional linkages with strong key authors (mainly within few Finnish universities) and multiple central boundary spanning scholars are linked together. On the other hand, some of the smaller network components are almost categorically clustered around one central author who bridges disconnected knowledge domains together through co-authorships (as shown in Appendices 1 and 2). These positions and structures could be explained through actor-specific attributes such as personality and academic tenure. For instance, as an established scholar in the field of innovation management, John Bessant seems to follow the structural hole / brokerage path in the co-authorship network, and a similar pattern is also seen in several other network components. These findings support the notion that the maturity of author's career affects chosen collaboration patterns (Price and Gursey, 1976). Based on social network theory arguments (e.g. Burt, 1992, 2004), such position could lead to more novel findings, solving potentially more complex problems. However, based on the results we cannot categorically say which type of networking practice is best, since it highly depends on the context and the purpose of co-authorships. In any case, we believe that our results provide some useful implications that can be used in further research, or in practice helping making more informed co-authorship decisions.

\subsection{Implications for practice}

In practical terms, the conducted social network analysis on the ISPIM community provides practical insights to the members of this particular community and beyond. It helps to analyse the structure and central actors in the innovation management network, which can be helpful in tracking e.g. key authors, prominent speakers, or potential places of collaboration within and beyond the community. For instance, connecting two central authors from disconnected sub-networks may provide significant opportunities for research collaboration both academically or in terms of research projects. Furthermore, our results may also help to evaluate innovation related research activities at country level, and help to track down central institutions conducting innovation management research in different countries.

Furthermore, in our view, the institutionally and geographically clustered nature of the examined co-authorship network is a natural consequence of the relevance of face-toface interaction in research work, as well as a matter of practicality - people tend to co- 
author with people they can easily interact with. However, international and interdisciplinary research collaboration is suggested to lead to valuable learning opportunities and contributions (Akkerman et al., 2006; Nissani, 1997). Therefore, in order to ensure the dissemination of knowledge, capabilities, and insights within the network, a larger amount of international collaboration could also be quite useful. This could also ensure inclusion of new members outside the current community. Thus, the results call for further and stronger international collaboration among the innovation management scholars of ISPIM and beyond. Such increased collaboration might require some type of institutional facilitating mechanisms or incentives coming from e.g. universities or scientific conferences. In fact, it is widely known that many leading academic institutions are encouraging their members towards more international collaboration through research exchanges and visits, for instance.

\subsection{Limitations and future research ideas}

Our study has limitations based on sample selection, unit of analysis and timeframe, which provide also basis for future research when combined with the presented findings. First, we focus solely on ISPIM, leaving out possible other avenues for research collaboration, including other conferences and journals. Second, the results are tied to formal co-authorships, and to the time period 2009-2011. Thus, the research admittedly leaves out many collaborative linkages that do exist between individual researchers outside the data analysed here. However, we believe that this study still provides a comprehensive outlook on the structure of the ISPIM community in its recent state.

To gain more insights beyond this study, further research could enlarge the timeframe to cover a longer time period, as well as find new network connections beyond the researcher and country-related linkages. In addition, an interesting avenue for further research could examine co-authorship networks dynamically over time, taking into account how and to what extent networks and central authors evolve (e.g. Wagner and Leydesdorff, 2005b). Further research could also include an approach focusing more on actors' attributes, such as personality, academic tenure and hierarchical position in their organizations to explain why they occupy certain structural positions. Indeed, attributes such as personality have been suggested to be combined with more traditional structural analyses (Kilduff and Brass, 2010; Morlacchi et al., 2005). Further research could also address the outcomes for central actors involved in networks with collective vs. structural-hole spanning properties, in terms of academic output, academic progression, future co-authorship patterns, or other measures.

\section{References}

Abt, H.A. (2007). The frequencies of multinational papers in various sciences. Scientometrics, Vol. 72, pp. 105-115.

Acedo, F. J., Barroso, C., Casanueva, C. and Galán, J.L, (2006), Co-Authorship in Management and Organizational Studies: An Empirical and Network Analysis, Journal of Management Studies Vol. 43, pp. 957-983.

Adler, N.J. (2002). International Dimensions of Organizational Behaviour (4 ed.), Cincinnati, OH: South-Western. 
Akkerman, S., Admiraal, W., Simons, R. and Niessen, T. (2006). Considering diversity: Multivoicedness in international academic collaboration. Culture Psychology, Vol. 12, pp. 461-485.

Allen, J., James, A., and Gamlen, P. (2007). Formal versus informal knowledge networks in R\&D: a case study using social network analysis. R\&D Management, Vol. 37, pp. 179-196.

Autry, C. W. and Griffis, S. E. (2005). A Social Anthropology of Logistics Research: Exploring Productivity and Collaboration in an Emerging Science. Transportation Journal, Vol. 44 (4), pp. 27-43.

Barabási, A., Jeong, H., Néda, Z., Ravasz, E., Schubert, A., and Vicsek, T. (2002). Evolution of the social networks of scientific collaborations. Physica, Vol. A311, pp. 590-614.

Barnett, A., Ault, R.W. and Kaserman, D.L. (1988). A Social Anthropology of Logistics Research: Exploring Productivity and Collaboration in an Emerging Science, Transport Journal, Vol. 44, No. 4, pp. 27-44

Beaver D. and Rosen R. (1978). Studies in scientific collaboration: Part I. The professional origins of scientific co-authorship. Scientometrics, Vol. 1, pp. 65-84.

Beaver D. and Rosen R. (1979a). Studies in scientific collaboration: Part II. Scientific coauthorship, research productivity, and visibility in the French scientific elite. Scientometrics, Vol. 1, pp. 139-149.

Beaver D. and Rosen R. (1979b). Studies in scientific collaboration: Part III. Professionalization and the natural history of modern scientific co-authorship. Scientometrics, Vol. 1, pp. 231245.

Beaver, D. deB., and R. Rosen. (1978). Studies in scientific collaboration. Pt.I, The professional origins of scientific co-authorship. Scientometrics, Vol. 1, pp. 65-84.

Beaver, D., (2001). Reflections on scientific collaboration (and its study): past, present, and future, Scientometrics, Vol. 52, pp. 365-377

Blau, P. (1964). Exchange and Power in Social Life. Wiley: New York.

Borgatti, S.P. and Everett, M.G. (1999). Models of core/periphery structures. Social Networks, Vol. 21, pp. 375-395.

Borgatti, S.P. and Foster, P.C. (2003). The network paradigm in organizational research: A review and typology. Journal of Management, Vol. 29, pp. 991-1013.

Borgatti, S.P., Everett, M.G. and Freeman, L.C. (1992). Ucinet - Guide - Ucinet for Windows: Software and Social Network Analysis. Harvard, MA: Analytic Technologies.

Borgatti, S.P., Mehra, A., Brass, D.J., and Labianca, G. (2009), Network analysis in social sciences. Science, Vol. 323, 892-895.

Bourdieu, P. (2004). Science of Science and Reflexivity. Cambridge: Polity.

Burt, R.S. (1992). Structural Holes: The Social Structure of Competition. Cambridge: Harvard University Press.

Burt, R.S. (2004). Structural holes and good ideas. American Journal of Sociology, Vol. 110, pp. 349-399.

Carter, C.R., Ellram, L.M. and Tate, W.. (2007). The use of social network analysis in logistics research, Journal of Business Logistics, vol. 28, pp. 137-168

Coleman, J.S. (1990). Foundations of Social Theory. Cambridge: Harvard University Press.

Cote, J. A., Leong, S. M., and Cote, J. (1991). Assessing the influence of journal of consumer research: A citation analysis. Journal of Consumer Research, Vol. 18(3), pp. 402-410.

Cronin, B., Shaw, D. and La Barre, K. (2003). A cast of thousands: co-authorship and subauthorship collaboration in the twentieth century as manifested in the scholarly literature of psychology and philosophy. Journal of the American Society for Information Science and Technology, Vol. 54, pp. 855-71 
Cross, R., Borgatti, S.P. and Parker, A. (2002). Making invisible work visible: using social network analysis to support strategic collaboration. California Management Review, Vol. 44(2), pp. 2547.

Egghe, L., (2006). Theory and practise of the g-index, Scientometrics, vol. 69, no. 1, pp. 131-152.

Fatt, C.K., Ujum, E.A., and Ratnavelu, K., (2010). The structure of collaboration in the Journal of Finance, Scientometrics, Vol. 85, pp. 849-860

Fischbach, K., Putzke, J., and Schoder, D., (2011), Co-authorship networks in electronic markets research, Electron Markets, Vol. 21, pp. 19-40

Freeman, L.C. (1979). Centrality in networks: Conceptual clarification, Social Networks, Vol. 1, pp. 215-239.

Gazni, A., Sugimoto, C. R., and Didegah, F. (2011). Mapping world scientific collaboration: authors, institutions, and countries. Journal of the American Society for Information Science and Technology, Vol. 63, pp. 323-335.

Glänzel, W., and De Lange, C. (2002). A distributional approach to multinationality measures of international scientific collaboration. Scientometrics, Vol. 54, pp. 75-89.

Goldfinch, S., Dale, T., and DeRouen, K. (2003). Science from the periphery: Collaboration, networks and 'Periphery Effects' in the citation of New Zealand Crown Research Institues articles, 1995-2000. Scientometrics, Vol. 57, pp. 321-337.

Granovetter, M. (1974). Getting a Job: A Study of Contacts and Careers. Cambridge: Harvard University Press.

Granovetter, M. (2005). The impact of social structure on economic outcomes. Journal of Economic Perspectives, Vol. 19, pp. 33-50.

Hawe, P, Webster, C., and Shiell, A. (2004). A glossary of terms for navigating the field of social network analysis. Journal of Epidemiology \& Community Health, Vol. 58, pp. 971-975.

Holder, M. E., Langrehr, F. W. and Schroeder, D. M. (2000). Finance journal coauthorship: how do coauthors in very select journals evaluate the experience?, Financial Practice and Education, Vol. 10, pp. 142-52.

Holt, K. (2006). ISPIM 1972-1985 (From conception to professional society). Web document. Available online: www.ispim.org/files/ISPIM_1972-1985.pdf.

Hu, C., and Racherla, P. (2008). Visual representation of knowledge networks: A social network analysis of hospitality research domain. International Journal of Hospitality Management, Vol. 27, pp. 302-312.

Hudson, J. (1996). Trends in multi-authored papers in economics, Journal Economics Perspectives, Vol. 10, pp. 153-8.

ISPIM (2012). History. Web document. Available online: http://www.ispim.org/\#about.

Kilduff, M. and Brass, D. J. (2010). Organizational social network research: Core ideas and key debates. Academy of Management Annals, Vol. 4, pp. 317-357.

Kuhn, T.S., (1962). The Structure of Scientific Revolutions, 1st. ed., Chicago: Univ. of Chicago Pr.

Laband, D. N. and Tollison, R. D. (2000). 'Intellectual collaboration'. Journal of Political Economy, Vol. 108, pp. 632-662.

Larivière, V., Gingras, Y., and Archambault, E. (2006). Canadian collaboration networks: A comparative analysis of the natural sciences, social sciences and the humanities, Scientometrics, Vol. 68, pp. 519-533

Laudel, G. (2001). Collaboration, creativity and rewards: Why and how scientists collaborate. International Journal of Technology Management, Vol. 22, pp. 762-781.

Leydesdorff, L., and Wagner, C.S. (2008). International collaboration in science and the formation of a core group. Journal of Informetrics, Vol. 2, pp. 317-325. 
Liu, X., Bollen, J., Nelson, M.L. and Van de Sompel, H. (2005). Co-authorship networks in the digital library research community. Information Processing \& Management, vol. 41, pp. 14621480

McPherson, J.M., Smith-Lovin, L. and Cook, J.M. (2001). Birds of a feather: Homophily in social networks. Annual Review of Sociology, Vol. 27, pp. 415-444.

Melin, G., (2000). Pragmatism and self-organization: Research collaboration on the individual level, Research policy, vol. 29, no. 1, pp. 31-40

Moody, J., (2004)- The structure of a social science collaboration network: disciplinary cohesion from 1963 to 1999. American Sociological Review, Vol. 69, pp. 213-38.

Morlacchi, P., Wilkinson, I. F. and Young, L. C. (2005). Social networks of researchers in B2B Marketing: A case study of the IMP Group 1984-1999. Journal of Business-to-Business Marketing, Vol. 12, pp. 3-34.

Newman, M. E. (2001). The structure of scientific collaboration networks. PNAS, Vol. 98, pp. 404-409.

Newman, M. E. (2004). Coauthorship networks and patterns of scientific collaboration. PNAS, Vol. 101, pp. 5200-5205.

Nissani, M. (1997). Ten cheers for interdisciplinarity: The case for interdisciplinary knowledge and research. The Social Science Journal, Vol. 34, pp. 201-216.

Onyancha, O.B., and Maluleka, J.R. (2011). Knowledge production through collaborative research in sub-Saharan Africa: How much do countries contribute to each other's knowledge output and citation impact? Scientometrics, Vol. 87, pp. 315-336.

Persson, O., Glänzel, W. and Danell, R. (2004). Inflationary bibliometric values: the role of scientific collaboration and the need for relative indicators in evaluative studies, Scientometrics, Vol. 60, pp. 421-432.

Pohl, C. and Hirsch Hadorn, G. 2007. Principles for designing transdisciplinary research. Munich: Oekom Verlag.

Price, D. and Gursey, S. (1976). Studies in scientometrics. Part 1. Transience and continuance in scientific authorship. In: International Forum on Information and Documentation, 17-24.

Price, D.J.D. (1963). Little Science, Big Science. New York: Columbia University Press.

Qin, J. (1994). An investigation of research collaboration in the sciences through the PhilosophicalTransactions 1901-1991. Scientometrics, Vol. 29, pp. 219-238.

Racherla, P. and Hu, C., (2010). A social network perspective of tourism research collaborations, Annals of Tourism Research, Vol. 37, No. 4, pp. 1012-1034.

Reagans, R. and McEvily, B. (2003). Network structure and knowledge transfer: The effects of cohesion and range. Administrative Science Quarterly, Vol. 48, pp. 240-267.

Robinson, L. and Adler, R. (1981). Measuring the impact of marketing scholars and institutions: and analysis of citation frequency. Journal of Academy of Marketing Science, Vol. 6, pp. 147162.

Rousseau, R. (2000). Are multi-authored articles cited more than singleauthored ones? Are collaborations with authors from other countries more cited than collaborations within the country?A case study (pp. 173-176).Proceedings of the Second BerlinWorkshop on Scientometrics and Informetrics,Collaboration in Science and in Technology, Free University, Berlin, 1-3 September.

Ruekert, R.W., and Walker, O.C. (1987). Marketing's interaction with other functional units: A conceptual framework and empirical evidence. Journal of Marketing, Vol. 51, pp. 1-19.

Santonen, T., Mokter, H. and Simula, H., (2012). An Evolutionary Network Analysis of Crowdsourcing Research Community, in Huizingh, K.R.E., Conn, S., Torkkeli, M., Bitran, I. (eds.), Proc. of The 5th ISPIM Innovation Symposium - Stimulating Innovation: Challenges for Management, Science \& Technology, 9-12 December, Seoul, Korea. 
Schmoch, U., and Schubert, T. (2008). Are international co-publications an indicator for quality of scientific research? Scientometrics, Vol. 74, pp. 361-377.

Schubert, T., and Sooryamoorthy, R. (2010). Can the centre-periphery model explain patterns of international scientific collaboration among threshold and industrialized countries? The case of South Africa and Germany. Scientometrics, Vol. 83, pp. 181-203.

Scott, J. P (2000). Social Network Analysis: A Handbook. SAGE Publications.

Song, M., and Montoya-Weiss, M. (2001). The effect of perceived technological uncertainty on Japanese new product development. Academy of Management Journal, Vol. 44, pp. 61-80.

Stokols, D., 2006, Toward a Science of Transdisciplinary Action Research, American Journal of Community Psychology, Vol. 38, pp. 63-77

$\mathrm{Su}, \mathrm{H}-\mathrm{N}$. and Lee, P-C. (2012). Framing the structure of global open innovation research. Journal of Informetrics, Vol. 6, pp. 202-216.

Tidd, J, Bessant, J. and Pavitt, K. (2005). Managing innovation. Integrating technological, market and organizational change. (3rd ed.), Chichester: Wiley.

Uzzi, B. (1996). The sources and consequences of embeddedness for the economic performance of organizations: The network effect. American Sociological Review, Vol. 61, pp. 674-698.

Wagner, C.S., and Leydesdorff, L., (2005a), Network structure, self-organization, and the growth of international collaboration in science, Research Policy Vol. 34, pp. 1608-1618

Wagner, C.S., and Leydesdorff, L., (2005b), Mapping the network of global science: comparing international co-authorships from 1990 to 2000. International Journal of Technology and Globalisation, Vol. 1, pp. 185-208.

Wagner, C.S., Brahmakulam, I., Jackson, B., Wong, A., and Yoda, T. (2001). Science and technology collaboration: Building capacities in developing countries. Santa Monica, CA: RAND.

Wasserman, S. and K. Faust (1994). Social Network Analysis: Methods and Applications. Cambridge: Cambridge University Press.

Watts, D. J. (1999) Small Worlds, Princeton, NJ: Princeton Univ. Press.

Vidgen, R., Henneberg, S. and Naudé, P. (2007). What sort of community is the European Conference on Information Systems? A social network analysis 1993-2005, European Journal of Information Systems, Vol. 16, pp. 5-19.

Yan, J. and Assimakopoulos, D. (2009). The small-world and scale-free structure of an internet technological community. International Journal of Information Technology and Management, Vol. 8, pp. 33-49.

Üsdiken, B. and Pasadeos, Y. (1995). Organizational analysis in North America and Europe: A comparison of co-citation networks. Organizational Studies, Vol. 16, pp. 503-536. 


\section{Appendix 1:}

\section{Appendix 1: Major components 2 to 5}

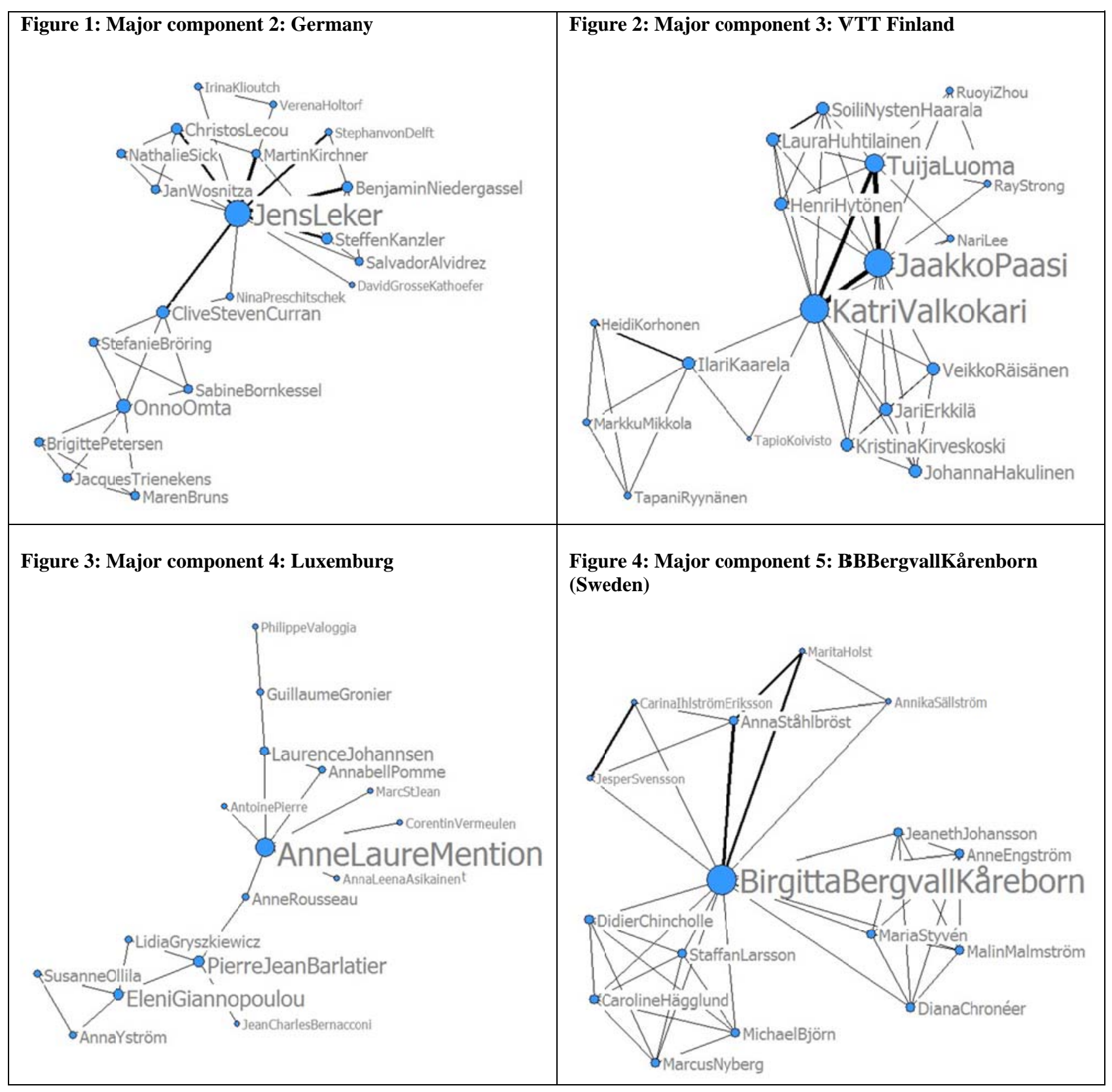


Appendix 2: Major components 6 to 9

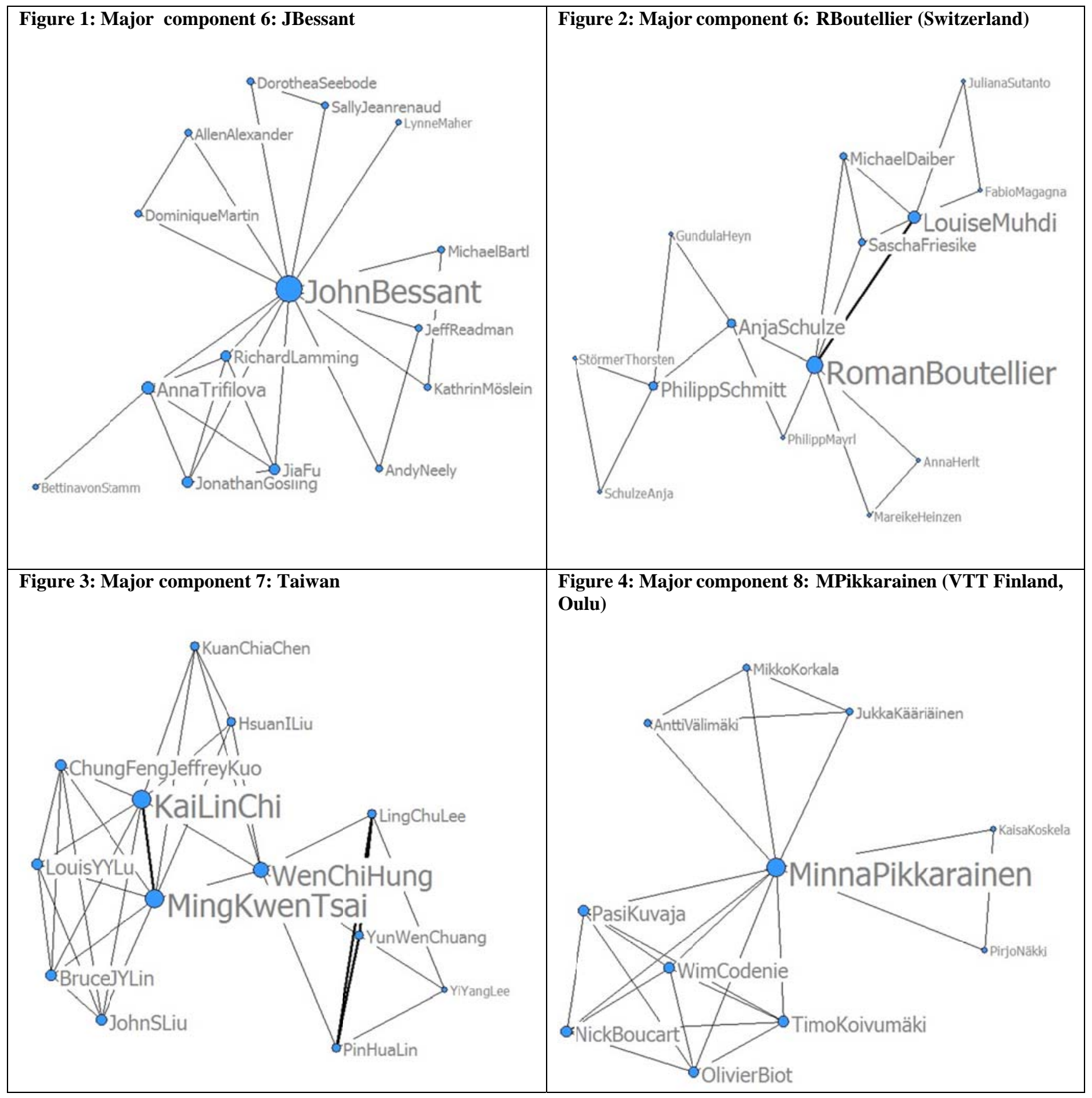

